\title{
Üroloji uzmanlık eğitimi alan öğrencilerin perkütan nefrolitotomi uygulama becerileri yeterli mi?
}

\author{
Mehmet Taşkıran', Mustafa Kadıhasanoğlư ${ }^{1}$, Mustafa Aydın², Umut Sarıoğulları', Hakan Şirin ${ }^{3}$, \\ Orhan Tanrıverdi ${ }^{1}$, Muammer Kendirci ${ }^{1}$, Cengiz Miroğlu ${ }^{1}$
}

\section{ÖZET:}

Üroloji uzmanlık eğitimi alan öğrencilerin perkütan nefrolitotomi uygulama becerileri yeterli mi?

Amaç: Perkütan nefrolitotomi (PCNL) operasyonu uygulanan bir klinikte üroloji uzmanlık eğitimi alan öğrencilerin PCNL uygulama becerilerinin uzmanlarla karşılaştırılması.

Gereçler ve Yöntem: Kasım 2004 - Ocak 2012 tarihleri arasında kliniğimizde yapılan 533 PCNL olgusu 2 gruba ayrılarak istatistiksel analiz için uygun olan veriler değerlendirildi. Grup-1 ( $n=431)$ : Kliniğin uzmanlarınca gerçekleştirilen operasyonlar; Grup-2 ( $n=102)$ : Eğitimlerini bu klinikte tamamlayan asistanlarca uzman gözetiminde yapılan operasyonlar olarak belirlendi. Her iki grup; yaş, cinsiyet, vücut kitle indeksi (VKi), operasyon süreleri, floroskopi süreleri, taş yüzey alanı, taş hacmi, kan transfüzyon oranları, böbreğe girilen port sayısı, hastanede kalış süreleri, taştan arınma oranları ve major komplikasyonlar göz önünde bulundurularak karşılaştırıldı. Iki gruptan elde edilen verilerin istatistiksel olarak karşılaştırılmasında ki-kare, student-t ve Mann-Whitney U testleri kullanıldı ve $p<0,05$ anlamlı kabul edildi.

Bulgular: Her iki grubun verileri değerlendirildiğinde, yapılan gruplar arası istatistiksel karşılaştırmada; cinsiyet, taş alanı, taş hacmi ve nefrostomi kateterlerini alma zamanları açısından istatistiksel anlamlı fark saptanmadı ( $p>0,05)$. Ayrıca, her iki grubun komplikasyon oranları ve transfüzyon gereksinimleri arasında da anlamlı fark izlenmedi. Ancak, Grup-2 tarafından uygulanan operasyonların ortalama hastanede kalış süreleri Grup-1'e göre anlamlı derecede daha kısa ve taşsızlık oranları da daha yüksek bulundu $(p<0,05)$. Benzer şekilde, floroskopi kullanım ve operasyon süreleri karşılaştıııdığında ise, Grup-2'nin verileri Grup-1'e göre anlamlı şekilde daha kısa bulundu.

Sonuç: Bu çalışmanın verileri, rutin olarak PCNL uygulanan bir klinikte tıpta uzmanlık öğrencilerinin de PCNL uygulama becerilerinin yeterli düzeye ulaşabileceğini göstermektedir.

Anahtar kelimeler: Perkütan nefrolitotomi, taş hastalığı, üroloji asistan eğitimi

\section{ABSTRACT:}

Are the urology residents capable of the ability of performing percutaneous nephrolithotomy?

Objective: To compare abilities of urology residents with attending surgeons in performing percutaneous nephrolithotomy (PCNL) in a clinic where PCNL procedures are performed.

Material and Methods: A total of 533 PCNL procedures between November 2004 and January 2012 were divided into two groups: Group $1(n=431)$ : PCNL procedures performed by experienced urologists and group-2 ( $n=102)$ : PCNL procedures performed by urology residents under supervision of experienced specialists. Patient's age, gender, body mass index, fluoroscopy and operation times, stone burden, rate of blood transfusion, number of access, hospital stay, stone free-status and major complication rates were statistically compared between these two groups. Data were provided as mean +/- SD. Chi-square, student-t and Mann-Whitney $U$ tests were used for statistical analyze and a p-value of fi0.05 was considered statistically significant.

Results: When compared two groups, there were no significant difference with regards to demographic variables, stone burden, rate of blood transfusion and major complication rates $(p>0,05)$. However, mean hospital stay and stone free rates in group- 2 were better than group-1 $(p<0,05)$. Also, mean fluoroscopy and operation time in group-2 were significantly shorter than in group-1.

Conclusions: These data demonstrated that the ability of urology residents for performing PCNL operation was found to be sufficient in a clinic where PCNL procedures are routinely performed. Key words: Percutaneous nephrolithotomy, renal stone disease, urology resident training program

Ş.E.E.A.H. Tıp Bülteni 2013;47(2):67-73
'Şişli Etfal Eğitim Ve Araştırma Hastanesi, İstanbul-Türkiye

${ }^{2}$ Hatay Kırıkhan Devlet Hastanesi, HatayTürkiye

${ }^{4}$ Trabzon Akçaabat Devlet Hastanesi,

Trabzon-Türkiye

Yazışma Adresi / Address reprint requests to: Op. Dr. Mehmet Taşkıran, Şişli Etfal Eğitim Ve Araştırma Hastanesi, İstanbul-Türkiye

Telefon / Phone: +90-212-373-5171

E-posta / E-mail:

mtskrn27@gmail.com

Geliş tarihi / Date of receipt:

14 Ekim 2012 / October 14, 2012

Kabul tarihi / Date of acceptance: 5 Kasım 2012 / November 5, 2012 


\section{Gíriş}

Antik çağlardan beri insanoğlunu etkileyen ve ülkemizde de endemik olan üriner sistem taş hastalığı, üriner enfeksiyonlar ve prostat hastalıklarından sonra üriner sistemi en çok etkileyen patoloji olup üroloji pratiğinin önemli kısmını teşkil etmektedir. Dünya çapında insanların yaklaşık \%5-15'ini etkilediği bilinmekte (1) ve son çeyrek yüzyılda da prevelansı giderek artış göstermektedir (2). Insan yaşamı süresince taş gelişim riski, gelişmiş ülkelerde \%10-15 iken Ortadoğu'da \%20-25'e kadar çıktığı gösterilmiştir (1). Taş hastalığına bu kadar sık rastlanılmakta, tedavisinde gelişen teknolojiyle birlikte endoürolojide cerrahi teknik ve ekipmanlar da gelişmektedir. Daha önceleri sıklıkla uygulanan açık cerrahi seçenekleri, günümüzde yerini minimal invaziv ya da daha az invaziv tedavi seçeneklerine bırakmış, şu anda çoğu merkezde açık cerrahi uygulama oranı \%1-10'lara gerilemiştir.

Gelişen yeni operasyon şekilleri bir çok cerrahı yeniden öğrenmeye, yeni tecrübeler kazanmaya, kursiyer olarak eğitim almaya mecbur kılmaktadır. Yeni bir operasyonu öğrenme yetisi uygun ortam, uygun zaman ve ilk planda daha az riskli olan uygun vakalar gerektirmesine rağmen yeterli tecrübe bir çok operasyon çeşidi için belirli sayıda uygulama gerektirmektedir. Öğrenme eğrisi, bir işte ustalık elde edebilmek için zamana karşı o işteki ustalığın gelişimini gösteren grafik olarak ifade edilir. Cerrahi tecrübeyle ilgili olan öğrenme eğrisi üzerine çıkan yayınların çoğu yeni uygulanmaya başlayan yöntemleri değerlendirmektedir.

Ürolojide öğrenme eğrisinin kullanımı, onkolojik cerrahi operasyonlarıyla $(3,4)$ laparoskopik girişimlerde başlamıştır $(5,6,7)$. Teorik bir konsept olan öğrenme eğrisi, daha çok radikal prostatektomi gibi operasyonların sonuçları üzerine oluşturulmuş nadiren diğer tekniklerde de kullanılmaya başlanmıştır. PCNL operasyonlarının öğrenme eğrisi daha zor olup başlangıçta daha çok komplikasyon yapıldığı görülmektedir. Bu girişimde yeterli cerrahi deneyimin kazanılması için yapılması gereken yeterli vaka sayısının belirlenmesi gerekmektedir. Her ne kadar PCNL'nin klinik başarısının ifadesinde taştan arınma ve komplikasyon oranları kullanılsa da öğrenme eğri- sinin tanımlanmasında operasyon ve skopi süreleri geçerlidir (8). Bu belirteçlerin kullanılmasıyla öğrenme eğrisinin belirlenmeye çalışıldığı çalışmalarda bir cerrah için ortalama 60 vakadan sonra operasyon ve skopi sürelerinin plato çizmeye başlayarak kendi değerlerini bulduğu saptanmıştır (8). Günümüzde endoskopik cerrahi teknikleri çoğu merkezde yaygın olarak uygulanmaktadır. Ülkemizde çoğu üroloji merkezi gelişmekte olup, PCNL operasyonları gün geçtikçe artarak yapılmaktadır. Ülkemizdeki üroloji kliniklerinde uzmanlık eğitimi alan asistan doktorların PCNL uygulamalarını değerlendiren çalışma bulunmamaktadır, çalışmaların çoğu uzman olan kişilerin öğrenim eğrisi üzerine yapılmıştır. Deneyim kazanmış kliniklerde eğitim alan kişiler daha az vaka sayısıyla daha kısa sürede yeterli tecrübe kazanabilirler.

Bu çalışmada perkütan nefrolitotomi (PCNL) operasyonu uygulanan bir klinikte uzmanlık eğitimi alan asistan doktorların PCNL uygulama becerilerinin, PCNL operasyonlarında deneyim kazanmış uzmanlarla karşılaştııılması amaçlanmaktadır.

\section{GEREÇLER ve YÖNTEM}

Çalışmaya Kasım 2004 ile Ocak 2012 tarihleri arasında kliniğimizde PCNL operasyonu uygulanmış 533 renal ünite dahil edildi. Her hasta için genel özellikleri, preoperatif, operatif ve postoperatif bilgiler prospektif olarak özel PCNL formuna kaydedildi. Daha sonra bu formlar retrospektif olarak değerlendirildi. Olgular, operasyonu yapan ürologa göre deneyim kazanmış uzmanlar ve eğitim alan asistan doktorlar şeklinde iki gruba ayrılarak karşılaştırıldı. PCNL operasyonunda deneyim kazanmış uzmanlar grup 1'i (n=431); tıpta uzmanlık eğitimi alan üroloji asistanlarının yaptığı girişimler grup 2'yi $(n=102)$ oluşturdu.

Çalışmaya alınan olguların genel özellikleri, preoperatif, operatif ve postoperatif verileri karşılaştırıldı (Tablo 1). Operasyon süresi, iğne ile giriş sağlanmasından nefrostomi kateterinin takılıp cilde sütüre edilerek işlemin sonlandırılmasına kadar geçen süre olarak kabul edildi. Taş alanı ve hacmi Avrupa Üroloji Birliği rehber kılavuzunda verilen formüllere göre direk üriner sistem grafisi (DÜSG) üzerinde elde edi- 
Tablo 1: Olguların çalışmada değerlendirilen verileri

\begin{tabular}{ll} 
Preoperatif veriler & Operatif veriler \\
\hline Daha önce ESWL tedavisi alma & Operasyon süresi \\
Daha önce PCNL uygulanma & Skopi süresi \\
Daha önce açık cerrahi uygulanma & Port sayısı \\
Ektazi & Girilen kaliks lokasyon \\
Taş alanı & \\
Taş hacmi & \\
Hemoglobin & \\
Hematokrit & \\
\hline ESWL; elektroşok dalgası ile taş kırma, PCNL; perkütan nefrolitotomi
\end{tabular}

\section{Postoperatif veriler}

Hemoglobin

Hematokrit

Komplikasyon

Transfüzyon oranı

Taştan arınma oranı

Nefrostomi tüpünün çekilme günü

Hastanede kalış süresi len ölçülere göre yapıldı. Operasyon sonrası çekilen DÜSG'de 4 mm ve altı taşlar klinik olarak anlamsız fragmanlar olarak kabul edildi. Opak olmayan taşların değerlendirmesinde, daha önceden intraperitoneal ya da retroperitoneal operasyon öyküsü olanlarda, kemik deformiteleri ya da böbrek anomalili olgularda spiral BT kullanıldı.

Operasyon öncesi hazırlıkta tüm hastaların idrar kültürünü de içeren laboratuar analizleri ve radyolojik görüntüleme çalışmaları yapıldı. İdrar kültürlerinde üreme olan hastalar, antibiyogramdaki sonuçlara göre uygun antibiyotiklerle tedavi edilip idrarlarının steril olması sağlandı. Genel anestezi indüksiyonu sağlandıktan sonra litotomi pozisyonu verilen hastalara toplayıcı sistemin boşluklarının opaklaşması ve genişlemesi için kontrast madde verilmesini sağlayacak olan $6 \mathrm{~F}$ açık uçlu üreter kateteri ipsilateral yerleştirilip foley katetere sabitlendi. Daha sonra hastalar, C kollu floroskopiyle uyumlu masa üzerinde prone pozisyona alınarak floroskopik kontrol altında uygun kaliksin değişik planlarda $C$ kolluyla görüntülenmesi yardımıyla $18 \mathrm{G}$ perkütan iğneyle giriş yapıldı. Toplayıcı sisteme kılavuz telin yerleştirilip tel üzerinden 14 F'e kadar yol dilate edildi. Dual lumen kateter üzerinden ikinci bir kılavuz tel güvenlik amacıyla yerleştirildi. Daha sonra balon dilatatör veya amplatz dilatatörlerle 30 F'e kadar dilatasyon sağlandı. $30 \mathrm{~F}$ amplatz kılıf içinden 24/26 F nefroskopla toplayıcı sisteme girilip pnömotik, ultrasonik veya kombine şekilde litotriptörler yardımıyla taşlar kırıldı ve kırılan parçalar da endoskopik kavrayıcılarla dışarı alındı. Operasyon sonrasında $14 \mathrm{~F}$ nefrostomi tüpü yerleştirilip cilde sabitlendikten sonra işleme son verildi.

Her iki grubun preoperatif, operatif ve postopera- tif verileri karşılaştırıldı. Bu çalışmada istatistiksel analizler, bilgisayar ortamında NCSS 2007 paket programı ile yapıldı. Tüm veriler ortalama \pm standart sapma olarak sunuldu. Her iki gruptaki veriler ki-kare, student-t ve Mann-Whitney $U$ testleriyle analiz edildi. Bu analizin sonuçlarına göre dağılımı normallik gösteren verilerin istatiksel analizinde parametrik testler, normallik göstermeyenlerin analizinde ise nonparametrik testler uygulandı. Verilerin değerlendirilmesinde gruplar arası karşılaştırmalarda bağımsız t testi, nitel verilerin karşılaştırmalarında ki-kare testi kullanılmıştır. Sonuçlar, anlamlılık $p<0,05$ düzeyinde değerlendirilmiştir.

\section{BULGULAR}

Kliniğimizde 2004 Kasım, 2012 Ocak ayları arasında yapılan 533 PCNL operasyonları grup 1 $(n=431)$ : deneyim kazanmış uzmanlar, grup 2 ( $n=102)$ : eğitim aşamasında olan asistan doktorların uyguladıkları vakalar şeklinde 2 gruba ayrıldı. Her iki grup hastaların karakteristik özellikleri, taşın bulunduğu taraf, taş yüzey alanı ve hacmi, taş lokalizasyonu, tedavi öncesinde elektroşok dalgası ile taş kırma (ESWL) uygulaması, önceden açık cerrahi ya da PCNL öyküsü, operasyon süresi, floroskopi süresi, port sayısı, kullanılan litotriptör, taştan arınma durumu, kan transfüzyon oranı, komplikasyon oranı, perkütan nefrostomi tüpünün çıkarılma zamanı, hastanede kalış süreleri ve ek tedavi gereksinimleri açısından karşılaştırıldı.

Her iki grup karşılaştırıldığında; yaş, cinsiyet, vücut kitle indeksi (VKi), taşın bulunduğu taraf (sağ/sol), ortalama taş alanı ve taş hacmi açısından istatistiksel olarak anlamlı farklılık saptanmadı $(p>0,05)$. Başarısız 
ESWL uygulaması sonrasında PCNL uygulanması açısından her iki grup arasında istatistiksel olarak anlamlı fark saptanmadı $(p=0,476)$. Daha öncesinde aynı taraf böbreğe taş nedeniyle açık cerrahi ya da PCNL uygulanmış sekonder vakalara grup 1 'de daha sık rastlanılmaktadır ( $p=0,001, p=0,023$ ) (Tablo 2).

Taşların yerleşim yerine bakıldı̆̆ında üst pol yerleşimli, tüm kalisyel yapıları dolduran geyik boynuzu taşların grup 1 de daha fazla oranda görüldüğü, istatistiksel olarak anlamlı olduğu saptanmıştır $(p=0,025)$. Grup-2'deki vakaların çoğunluğunun taşların orta $(\% 38,2)$ ve alt $(\% 39,2)$ kalisyel yerleşimli olduğu, grup 1'le karşılaştırıldığında istatistiksel olarak anlamI ı ve daha yüksek oranda olduğu saptanmıştır $(p=0,025)$ (Tablo 3).
Her iki grup operasyon ve floroskopi süreleri açısından karşılaştırıldığında Grup 2 tarafından yapılan vakaların daha kısa sürede yapıldığı, operasyon esnasında daha az floroskopi uygulandığı istatistiksel olarak anlamlı bulunmuştur. Böbreğe girilen ortalama port sayısı grup 1'deki vakalarda istatistiksel olarak anlamlı daha yüksek bulunmuştur. Taş yüzey alanı ve taş hacmi istatistiksel olarak her iki grupta benzer bulunmasına rağmen, taştan arınmanın grup-2'de daha yüksek oranda sağlandığı tespit edilmiştir. Kan transfüzyon oranı, komplikasyon oranı ve perkütan nefrostomi kateterinin alınma zamanı her iki grupta istatistiksel olarak benzer bulunmasına rağmen, hastanede kalış sürelerinin Grup 2'de daha kısa olduğu tespit edilmiştir (Tablo 4). 533 PCNL prosedürünün

Tablo 2: Hastaların operasyon öncesi verilerinin değerlendirilmesi

\begin{tabular}{llll}
\hline & Grup 1 (n=431) & Grup 2 (n=102) & P \\
\hline Yaş (yıl) & $41,91 \pm 15,76$ & $42,9 \pm 13,94$ & 0,617 \\
Cinsiyet (K/E) & $184 / 247$ & $37 / 65$ & 0,236 \\
VKi $\left(\mathrm{kg} / \mathrm{m}^{2}\right)$ & $26,06 \pm 6,73$ & $28,42 \pm 7,03$ & 0,052 \\
Taşın bulunduğu taraf (sağ/sol) & $194 / 237$ & $41 / 61$ & 0,342 \\
Daha önce ESWL & $\% 24,3$ & $\% 25,2$ & $\mathrm{p}=0,476$ \\
Daha önce PCNL & $\% 5,2$ & $\% 2,3$ & $\mathrm{p}=0,023 *$ \\
Daha önce açık cerrahi & $\% 14,4$ & $\% 1,6$ & $\mathrm{p}=0,001^{*}$ \\
Ortalama Taş Yüzey Alanı $\left(\mathrm{mm}^{2}\right)$ & $973,86 \pm 1050,09$ & $915,07 \pm 1095,31$ & 0,161 \\
Ortalama Taş Hacmi $\left(\mathrm{mm}^{3}\right)$ & $4300,5 \pm 6415,22$ & $4092,33 \pm 6384,15$ & 0,161 \\
\hline
\end{tabular}

ESWL; elektroşok dalgası ile taş kırma, PCNL; perkütan nefrolitotomi

Tablo 3: Gruplara göre böbrekteki taşların lokalizasyonu

\begin{tabular}{llll}
\hline Kaliks [n (\%)] & Grup 1 & Grup 2 & P \\
\hline Üst & $35(\% 8,2)$ & $2(\% 1,96)$ & 0,025 \\
Orta & $96(\% 22,5)$ & $39(\% 38,2)$ & $40(\% 39,2)$ \\
Alt & $175(\% 40,7)$ & $4(\% 3,92)$ & - \\
Üst+Orta & $9(\% 2,2)$ & $12(\% 11,76)$ & $5(\% 4,9)$ \\
Üst+Alt & $21(\% 4,9)$ & $64(\% 15,4)$ &
\end{tabular}

Tablo 4: Operasyon ve operasyon sonrası verilerinin değerlendirilmesi

\begin{tabular}{llll}
\hline & Grup 1 & Grup 2 & P \\
\hline Ortalama operasyon süresi (dk.) & $130,51 \pm 56,64$ & $112,47 \pm 51,32$ & $0,008^{*}$ \\
Ortalama floroskopi süresi (dk.) & $6,73 \pm 6,55$ & $4,32 \pm 3,46$ & $0,005^{*}$ \\
Kan transfüzyon oranı (\%) & 14,32 & 11,11 & 0,468 \\
Ortalama port sayısı & $1,36 \pm 0,64$ & $1,19 \pm 0,49$ & $0,032^{*}$ \\
Komplikasyon oranı (\%) & 6,9 & 5,5 & 0,67 \\
Taştan arınma oranı (\%) & 68,03 & 80 & $0,033^{*}$ \\
Perkütan nefrostomi tüpünün çıkarılması (gün) & $3,51 \pm 1,74$ & $3,33 \pm 1,56$ & 0,264 \\
Hastanede kalış süreleri (gün) & $5,6 \pm 2,92$ & $4,64 \pm 1,77$ & $0,008^{*}$
\end{tabular}


39'unda major komplikasyon gelişmiştir. Grup-1'de 33 vakada, grup 2'de 6 vakada major komplikasyon görülmüştür. Görülen major komplikasyonlar Clavien sınıflamasına göre gruplandırıldığında grup 1 'de 3 vakada sepsis (derece 4b), 1 vakada kolon perforasyonu (derece 4a), 2 vakada hemotoraks (derece 4a), 1 vakada lober pnömoni (derece 2), 26 vakada operasyonun durdurulmasını gerektiren ya da operasyondan sonra da devam edip transfüzyon ihtiyacı olan kanamalar (derece 2) görülmüştür. Grup-2'de 1 vakada pelvis perforasyonu (derece 3a), 5 vakada transfüzyon ihtiyacı olan kanamalar görülmüş olup (derece 2), masif kanamadan dolayı 1 hastaya nefrektomi (derece 4a) uygulanmıştır.

\section{TARTIŞMA}

İlk defa 1976 yılında tarif edilen PCNL, geçtiğimiz 30 yıl içinde böbrek taşlarının tedavisinde düşük komplikasyon ve yüksek başarı oranlarıyla ilk planda tercih edilen standart bir yöntemdir. Tüm bu avantajlar, PCNL'yi mutlak öğrenilmesi gereken operasyon haline getirmiştir. Buna rağmen öğrenme eğrisinin zor olduğunun düşünülmesi ürologları bu operasyonu öğrenmede çekingen kılmaktadır (9). Öğrenmeyi zorlaştıran faktörlerden önde geleni PCNL'nin en zor ve önemli basamağı olan toplayıcı sisteme giriştir. Amerika Birleşik Devletleri'nde eğitim yetersizliği, kişisel tercihler, radyoloji ünitelerindeki ekipmanların daha iyi olduğunun düşünülmesi, zamandan tasarruf gibi nedenlerle ürologların sadece $\% 11^{\prime} \mathrm{i}$

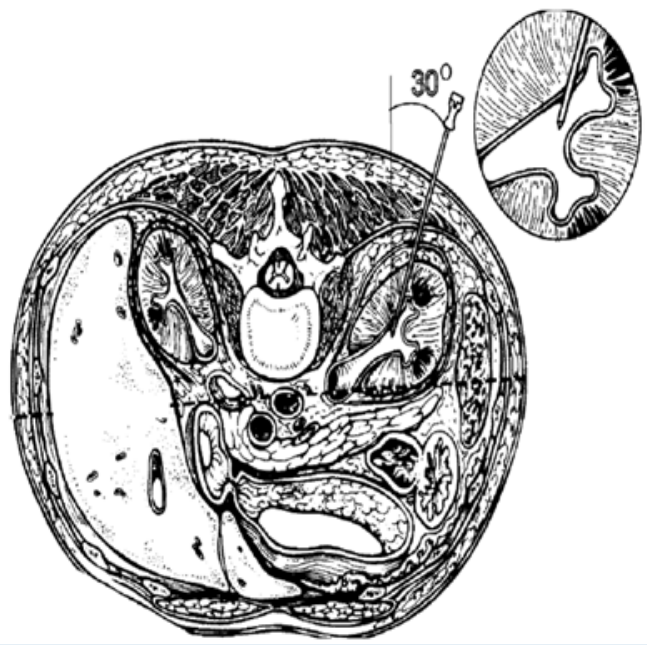

Şekil 1: Posterior fornisyel giriş (11) renal girişi kendileri sağlamaktadır (9). Uygun giriş sağlandıktan sonra hem yeterli taştan arınma sağlanır hem de ciddi vasküler yaralanmaların önüne geçilmiş olur (10).

PCNL operasyonlarında yeterli cerrahi tecrübenin sağlanması için kaç vakanın yapılması gerektiği çok önemli bir konudur. Tanrıverdi ve arkadaşları tarafından yapılan çalışmada PCNL için öğrenme eğrisi tanımlanmış ve bir cerrahın 60 vakadan sonra kendi ortalama operasyon ve skopi sürelerine ulaştığı gösterilmiştir (8). Bu konuda yapılan bir diğer çalışmada Allen ve arkadaşları, 60 vakadan sonra ortalama operasyon süresinin anlamlı olarak değişmediğini; skopi süreleriyle radyasyon dozlarınınsa 115 vakadan sonra plato çizmeye başladığını saptamışlardır (12). Bu iki çalışmadan elde edilen ortak sonuçlara göre daha önce tek başına PCNL tecrübesi olmayan bir cerrahın yaptığı operasyonlardan elde edilen operasyon ve skopi sürelerinin değerlendirilmesinde artan vaka tecrübesiyle bu sürelerde dereceli bir azalma ve belirli bir vaka sayısına ulaşıldıktan sonra da kendi ortalama değerlerine ulaşıldığı görülmektedir.

Fakat üroloji uzmanlık eğitimi alan bir kişinin eğitim süreci içerisinde yeterli PCNL eğitimi açısından değerlendirilen bir çalışma bulunmamaktadır. Bu çalışmada asistan doktorlar, uzmanlık eğitimlerinin ilk yılından itibaren endoskopik girişimleri en basitinden başlayarak öğrenmeye ve uygulamaya başlamaktadır. Öncelikle üretrosistoskopi, yeterli sayıda üreterorenoskopi, transüretral prostat rezeksiyonu, mesane tümörünün transüretral rezeksiyonu sistolitotripsi ve benzeri operasyonları yapabildikten ve PCNL deneyimi olan uzman kişileri yeterli düzeyde asiste ettikten sonra, uzman kişiler gözetiminde seçilmiş böbrek taşlı vakalara PCNL operasyonu uygulamışlardır. Çalışmamızdan elde edilen bulgular, ülkemizde üroloji uzmanlık eğitimi alan kişilerin yeterli düzeyde PCNL uygulayabilirliklerini gösteren ilk çalışmadır. PCNL deneyimi kazanmış uzman kişiler ilk yaptıkları PCNL operasyonlarından bu zamana kadar değerlendirildiğinde, cerrahi tecrübe arttıkça öğrenme eğrisini oluşturan en önemli faktörler olan operasyon ve skopi sürelerinde başlangıca göre ciddi bir azalma görüldüğü ve belirli bir operasyon sayısına ulaştıktan sonra kendi ortalama değerlerini oluşturdukları izlenmiştir. Bu çalışmada yeterli endosko- 
pik girişim deneyimi olan ve farklı zamanlarda farklı kişiler tarafından yapılmış PCNL vakaları değerlendirildiğinde grup 2'deki vakaların operasyon ve floroskopi sürelerinin daha kısa olduğu göze çarpmaktadır. Çünkü asistan doktorlar tarafından yapılan vakalar, daha önce açık cerrahi öyküsü, komorbiditesi, böbrek anomalisi, kemik deformitesi olmayıp, çoğunlukla taşları pelvis, alt pol ya da orta pol yerleşimli olan seçilmiş kişilerden oluşmaktadır. Yine bu vakalar yapılırken, uzman gözetiminde gereğinde asistan doktor yönlendirilerek yardımcı olunan vakalardır.

PCNL operasyonun en önemli ve zaman harcanan basamağı, böbreğe uygun kaliksten girişin sağlanması ve yolun genişletilerek amplatz kılıfın yerleştirilmesidir. Gelişen kalisyel giriş tekniği, operasyon ve skopi sürelerinin azalmasını sağlamaktadır. Cerrahi ustalığın tanımlanmasında kullanılan iki parametre olan operasyon ve skopi sürelerinin vaka sayısı arttıkça azaldığının görülmesi cerrahın endoskopik aletlere alışmasına ve böbreğe giriş sırasında floroskopiden elde edilen iki boyutlu görüntüleri zihninde işleyerek üç boyutlu kalisyel anatomiyi canlandırmasındaki gelişmeye bağlı olabileceği düşünülebilir. Cerrahi tecrübenin gelişmesiyle böbreğe giriş daha kolaylaşmakta ve bu da operasyon ve skopi sürelerini ciddi biçimde etkilemektedir.

Taştan arınma konusunda da literatürde \%51 ile $\% 100$ arasında oranlar verilmekte ve bu oranlar, taş yükü, sayısı, lokalizasyonu, kalisyel divertikül olup olmaması, böbrek anomalileri, daha önce cerrahi geçi- rip geçirmemesi ve obeziteden etkilenmektedir (13). ilk grupta yapılan 431 operasyonda toplam 33, ikinci grupta da 102 vakada toplam 6 major komplikasyon görülmüştür. Birinci grupta ortalama taştan arınma oranı \%68,03 olup ikinci grupta ise \%80'dir. İki oran arasında istatiksel olarak anlamlı farklılıklar izlenmiştir.

Port sayısı artıkça operasyon süresinde artışa neden (14) olduğu bilinmekle beraber, Grup 1'de böbreğe girilen ortalama port sayısının daha yüksek olduğu, komplikasyonların çoğunluğunun böbreğe çoklu giriş yapılan olgularda görülmesi dikkat çekmektedir. Grupların transfüzyon oranları, operasyon öncesi ve sonrası hemoglobin ve hematokrit değerleri de incelendiğinde belirgin bir farklılık göze çarpmamaktadır. Kanama ve transfüzyon oranlarının benzer ve literatürde bildirilen \%6-23 arasındaki değerler (15) arasında olduğu görülmektedir. Perkütan nefrostomi kateterlerinin alınma zamanları her iki grupta benzer olmasına rağmen hastanede kalış süresi grup 1'de daha yüksek bulunmuştur.

Bu çalışma, üroloji alanında uzmanlık eğitimi alan asistan doktorların belirli endoskopik girişimleri basitten zora doğru belirli bir sırayla yapması ve yeterli derecede PCNL asistansı yapması sonucunda seçilmiş vakalardan başlayarak başarılı bir şekilde PCNL operasyonlarını uygulayabileceklerini göstermektedir. Deneyimli bir merkezde PCNL eğitimi almış ve öğrenim eğrisini tamamlamış bir cerrahın bulunması, sonraki cerrahların PCNL eğitimini daha kısa sürede tamamlamasına katkı sağlayabilmektedir.

\section{KAYNAKLAR}

1. Moa OW: Kidney stones: Pathophysiology and medical management. Lancet 2006;367:333-344.

2. Stamatelou KK, Francis ME, Jones CA, Nyberg LM, Curhan GC: Time trends in reported prevalence of kidney stones in the united states: 1976-1994. Kidney Int 2003;63:1817-1823.

3. El-Feel A, Davis JW, Deger $S$, et al Positive margins after laparoscopic radical prostatectomy: A prospective study of 100 cases performed by 4 different surgeons. Eur Urol 2003;43:622626.

4. Singh $R$, Smeeton $N, O^{\prime} B r i e n ~ T S$ : Identifying under-performing surgeons. BJU Int 2003;91:780-784.

5. Dalla Valle R, Mazzoni MP, Capocasale E, et al: Laparoscopic donor nephrectomy: Short learning curve. Transplant Proc 2006;38:1001-1002.

6. Ficarra V, Cavalleri S, Novara G, Aragona M, Artibani W: Evidence from robot-assisted laparoscopic radical prostatectomy: A systematic review. Eur Urol 2007;51:45-55.

7. Poulakis V, Dillenburg W, Moeckel M, et al: Laparoscopic radical prostatectomy: Prospective evaluation of the learning curve. Eur Urol 2005;47:167-175.

8. Tanriverdi O, Boylu U, Kendirci M, Kadihasanoglu M, Horasanli $K$, Miroglu C: The learning curve in the training of percutaneous nephrolithotomy. Eur Urol 2007;52:206-211.

9. De la Rosette JJ, Laguna MP, Rassweiler JJ, Conort P: Training in percutaneous nephrolithotomy--a critical review. Eur Urol 2008;54:994-1001.

10. Watterson JD, Soon S, Jana K: Access related complications during percutaneous nephrolithotomy: Urology versus radiology at a single academic institution. J Urol 2006;176:142-145.

11. Clayman RV, Castaneda-Zuniga WR: A guide to the percutaneous removal of renal and ureteral calculi; Techniques in endourology. Dallas, Heritage Press, 1984

12. Allen $D, O^{\prime}$ Brien $T$, Tiptaft $R$, Glass J: Defining the learning curve for percutaneous nephrolithotomy. J Endourol 2005;19:279-282. 
M. Taşkıran, M. Kadıhasanoğlu, M. Aydın, U. Sarıoğulları, H. Şirin, O. Tanrıverdi, M. Kendirci, C. Miroğlu

13. Skolarikos A Alivizatos $G$ de la Rosette IJ: Percutaneous nephrolithotomy and its legacy. Eur Urol 2005;47:22-28.

14. Netto NR Jr, Ikonomidis J, Ikari O, Claro JA: Comparative study of percutaneous access for stagSegura JW, Patterson DE, LeRoy AJ, Williams HJ Jr, Barrett DM, Benson RC Jr, May GR, Bender CE:

Percutaneous removal of kidney stones: Review of 1,000 cases. J Urol 1985;134:1077-1081.
15. Lingeman JE, Coury TA, Newman DM, Kahnoski RJ, et al. Comparison of results and morbidity of percutaneous nephrostolithotomy and extracorporeal shock wave lithotripsy. J Urol 1987; 138. 